\title{
Formação Continuada de Professores para as TIC: Análise a Partir dos Cursos Ofertados pelo NTE-Natal
}

\author{
Rodrigo R. M. de Lima ${ }^{1}$, Wamberto J. F. de Lima ${ }^{1}$, Dennys Leite Maia ${ }^{1}$ \\ ${ }^{1}$ Instituto Metrópole Digital - Universidade Federal do Rio Grande do Norte (UFRN) \\ Avenida Senador Salgado Filho, 3000 - Lagoa Nova - 59.078-970 - Natal - RN - \\ Brazil \\ rodrigorodriguesml@gmail.com, wambertolima@hotmail.com, \\ dennys@imd.ufrn.br
}

\begin{abstract}
Teachers' continuous formation is essential for their pedagogic practices update. The use of communication and information technologies (CITs) inside the scholar environment is already real, however it is necessary the teachers' knowledge for applying it at education. In the city of Natal-RN, this formation is offered by the Educational Technology Center (NTE-Natal). Through bibliographic researches and data collect acquired at this Center, it was possible analyze important issues whose may support the NTE-Natal growth. With this study, it was possible to identify the relevancy of works done at NTE for the continuous formation of teachers from Natal public schools using the CITs pedagogically.
\end{abstract}

Resumo. A formação continuada de professores é fundamental para a atualização de suas práticas pedagógicas. O emprego das tecnologias da informação e comunicação (TIC) no âmbito escolar já é uma realidade, mas se faz necessário o conhecimento dos professores para aplicá-las na educação. Na cidade de Natal$R N$, essa formação é oferecida pelo Núcleo de Tecnologia Educacional (NTENatal). Através de pesquisas bibliográficas e coleta de dados obtidos desse núcleo, foi possivel analisar fatores importantes que podem servir de subsídios para o crescimento do NTE-Natal. Com este estudo, identificamos a relevância dos trabalhos realizados no NTE para a formação continuada dos professores da Rede Municipal de Ensino de Natal no uso pedagógico das TIC.

\section{Introdução}

A formação continuada de professores é fundamental para a atualização de suas práticas pedagógicas. Isto tem relevância maior quando se trata de uma área suscetível a mudanças e atualizações frequentes, como é o caso das Tecnologias da Informação e Comunicação (TIC) na Educação. Nessa conjuntura, parece haver uma relação entre o pouco uso pedagógico das TIC nas escolas, com a falta de conhecimento ou prática no uso das mesmas por parte dos professores.

Como destacam Maia e Barreto (2012) é necessário que gestores e professores percebam as TIC como instrumentos não somente para serem utilizados de forma pontual, mas integrado ao cotidiano da escola e que passem a perceber que tais recursos podem contribuir para o desenvolvimento cognitivo e social dos educandos. As TIC, por seu caráter multimidiático, proporcionam diferentes formas de apresentar o conteúdo e representar os conceitos trabalhados nas diversas áreas do conhecimento. Para tanto, é 
fundamental que os professores conheçam as possibilidades que podem se servir e tenham acesso em suas formações - inicial e continuada - a esses conhecimentos.

Há mais de uma década Mercado (1999, p. 12) já alertava, e ainda vale para a atualidade, que é exigido "dos professores que saibam incorporar e utilizar as novas tecnologias no processo de aprendizagem”. Assim sendo, é aconselhável que o professor deixe a estaticidade em que se encontra para que dinamize sua formação profissional continuada passando a ter uma gama maior de conhecimentos. Se o professor não se adequar as TIC para uso educacional, pode limitar as possibilidades pedagógicas que pode se servir para melhorar suas aulas. Conhecer o potencial desses novos auxiliadores didáticos não é somente uma questão de adequação ao atual contexto sócio tecnológico, mas de ressignificar as práticas de ensino e aprendizagem, empregando-os nas salas de aula.

Contudo, aos professores não cabe todo o ônus da não utilização ou subtilização das TIC nas práticas educativas. Ainda são poucas as condições e oferta de formações para o desenvolvimento dessa área. A esse respeito Maia e Barreto (2012, p. 51) pontuam que:

\begin{abstract}
As experiências propostas pelo poder público, no sentido de capacitar o professor a trabalhar com as tecnologias digitais nos ambientes escolares, são, via de regra, desarticuladas da formação inicial de professores. Nos currículos das licenciaturas, as tecnologias não têm ainda um lugar de destaque. A ênfase no processo de capacitação recai sobre a formação continuada.
\end{abstract}

Diante dessa realidade os Núcleos de Tecnologia Educacional (NTE), criados a partir de políticas públicas dos anos 1990 (MAIA; BARRETO, 2012), aparecem como importante segmento na formação continuada de professores para o uso pedagógico das TIC. Estes espaços são unidades dotadas de infraestrutura de informática e comunicação, que reúnem equipes de educadores e especialistas em tecnologia de hardware e software para o uso educativo. Os profissionais que trabalham nos NTE são especialmente capacitados pelo Programa Nacional de Tecnologia Educacional (PROINFO) para auxiliar as escolas em todas as fases do processo de incorporação e uso pleno das TIC, em atividades didático-pedagógicas.

Desta feita, foi implantado na cidade do Natal, capital do Rio Grande do Norte (RN), o NTE-Natal, através da Lei Complementar $\mathrm{N}^{\circ}$ 67, de 24 de novembro de 2005, reformulada pela Lei Complementar $\mathrm{N}^{\mathrm{0}}$ 77, de 28 de novembro de 2006, do Prefeito Municipal do Natal. Neste documento são asseguradas as condições pedagógicas, administrativas e financeiras para o ensino da informática educativa e para $o$ acompanhamento e avaliação dos projetos pedagógicos de informática, bem como a manutenção e a plena utilização dos equipamentos do Programa de Informática Educativa, nos laboratórios do NTE. Portanto, desde sua concepção, o NTE-Natal configura-se como um espaço destinado à capacitação e aperfeiçoamento dos professores da rede pública municipal, nos três turnos, especialmente quanto ao uso das TIC em suas atividades pedagógicas.

Diante desse contexto, o objetivo deste estudo é analisar o potencial formativo do NTE-Natal para a formação continuada de professores para as TIC, a partir da diversidade de cursos oferecidos. Baseados numa apreciação quantitativa e descritiva do rol de cursos ofertados pela referido núcleo, esperamos captar e refletir sobre este aspecto do potencial formativo. Este estudo levou em conta os cursos oferecidos pela instituição, relacionando com a proposta do NTE, a periodicidade de oferta e o número 
efetivo de professores matriculados e concludentes nesses cursos. Nas seções a seguir, apresentamos o quadro teórico e o percurso metodológico que nortearam nossas análises.

\title{
2. Formação Continuada de Professores para o Uso Pedagógico das TIC
}

Vivemos em uma era eminentemente tecnológica e em todos os campos da sociedade se faz necessário ter o mínimo de conhecimento para lidarmos com as diversas tecnologias que nos são apresentadas diariamente. No campo da Educação não é diferente. $O$ emprego das TIC no âmbito escolar já é uma realidade e em função disso, é um tema bastante discutido pelos pesquisadores da área das TIC na Educação. Como destaca Quartieiro (2010, p. 555 - grifos nossos):

\begin{abstract}
O desenvolvimento de artefatos tecnológicos específicos para as instituições escolares, assim como a incorporação de tecnologias concebidas para outras frentes - tais como o rádio, a televisão e o computador - vão demandar pesquisas sobre a criação, desenvolvimento, metodologias e avaliação desses meios e materiais nos espaços educativos e, principalmente, a discussão sobre a formação de professores necessária para essa incorporação.
\end{abstract}

Por conseguinte, demanda-se que o docente se insira nesse contexto tecnológico, a fim de promover o seu aperfeiçoamento, não ficando alheio às mudanças sociais, educacionais e culturais, comuns do atual contexto. Isto tem importância, haja vista que os seus alunos também compartilham dessas mudanças e na sua maioria já fazem uso das TIC no seu cotidiano.

Aliada à necessidade de continuidade na formação docente, o Governo Federal brasileiro criou em 1997 o Programa Nacional de Informática na Educação (ProInfo), estruturado de forma descentralizada em Núcleos de Tecnologia Educacional (NTE), os quais são ligados às Secretarias Estaduais de Educação ou às Secretarias Municipais de Educação.

Dentre as características já citadas, cada NTE deve desenvolver as seguintes ações específicas: i) Sensibilizar e motivar dirigentes e professores das escolas no sentido da incorporação das TIC no processo de ensino e aprendizagem; ii) Capacitar e atualizar professores e equipes administrativas das escolas; iii) Apoiar o processo de planejamento e gestão de uso das TIC nas escolas; $i v$ ) Dar assessoramento pedagógico ao uso da TIC nos processos de ensino e aprendizagem; v) Apoiar a resolução de problemas técnicos decorrentes do uso do computador nas escolas; e vi) Realizar acompanhamento e avaliação local do processo de incorporação da TI no processo didático-pedagógico. Tais ações visam contribuir para a integração das TIC em sala de aula por professores, explorando seus potenciais favoráveis ao ensino e a aprendizagem.

Segundo Quartiero (2010, p. 554) “os NTE foram criados com a função de organizar e executar processos de formação de professores para o uso e incorporação do computador no processo de ensino-aprendizagem". Com este propósito, foram criados e distribuídos cem NTE por todo país, com no mínimo um em cada estado (MAIA, BARRETO, 2012). No Estado do Rio Grande no Norte, em 2005, foi instalado e concebido o NTE do município de Natal para viabilizar a disseminação e manutenção de TIC nas escolas e a formação de professores para o uso pedagógico desses auxiliadores didáticos na capital potiguar.

O NTE-Natal está subordinado administrativamente ao Departamento de Ensino da Secretaria Municipal de Educação, a quem cabe prover os meios físicos, financeiros e 
a infraestrutura administrativa que garantam as condições pedagógicas de seu funcionamento. Entre as diversas missões do NTE-Natal, destaca-se a de promover a formação dos profissionais da educação pública para o uso das TIC, incentivando e orientando o desenvolvimento de trabalhos e pesquisas que busquem a criação de novas formas de uso dessas tecnologias como recursos didáticos auxiliares nos processos de ensino e de aprendizagem.

Neste sentido, os professores precisam ser formados tanto para o aspecto técnico do uso das TIC, mas sobretudo, para o aspecto pedagógico. É relevante que a formação oferecida em cursos após a licenciatura, com o professor já em serviço, portanto, formação continuada, contemple a familiarização docente com as TIC, neste caso os hardwares (computadores, tablets etc) e seus softwares, relacionando-os, sempre que possível, com sua prática em sala de aula. Para tanto, é fundamental que haja flexibilidade quanto a oferta e horários dos cursos, bem como da gestão para garantir ao professor cursar e concluir as formações. Isto resulta em algo positivo para a apropriação das TIC pelo professor, pois além de dedicar tempo para a sua formação, ele tem a possibilidade de refletir sobre tais ferramentas a partir da e na sua ação docente.

Uma diversidade de cursos oferecidos, com diferentes focos, explorando a utilização de diferentes softwares e outros recursos educacionais digitais, contribui de forma significativa para que o professor conheça diferentes estratégias didáticas com a utilização das TIC em sala de aula. Ademais, a cada dia, novas ferramentas e possibilidades pedagógicas com as TIC são desenvolvidas. Isto reforça a necessidade de existir cada vez mais cursos, sobretudo de formação continuada, com diferentes ferramentas e conteúdos, que oportunizem novos possibilidades ao professor para ministrar suas aulas.

\section{Metodologia}

Este trabalho é fruto de uma disciplina do curso de Bacharelado em Tecnologia da Informação (BTI), com ênfase em Informática Educacional, do Instituto Metrópole Digital (IMD) da Universidade Federal do Rio Grande do Norte (UFRN). A referida disciplina tem, dentre outros objetivos, conhecer a realidade da formação docente para o uso pedagógico das TIC. Com isto, espera-se que o egresso do referido curso, contribua no desenvolvimento de ações e ferramentas em favor da disseminação da Informática Educativa no Estado, articulando de forma interdisciplinar duas áreas do conhecimento Computação e Educação. Neste sentido, conhecer como se dá a formação docente para o uso dessas ferramentas é fundamental para empreendimentos futuros.

Para a coleta de dados foram realizadas pesquisas em fontes bibliográficas e documentais. A primeira diz respeito à temática abordada, para basear as análises. A segunda, focou-se registros acerca do NTE-Natal e dos cursos por ele oferecidos, o que proporcionou as condições necessárias para efetivar à análise objetivada. Registre-se que nada foi encontrado sobre relatos de pesquisa acerca dos cursos de formação e o potencial formativo do NTE-Natal. Consideramos que isto reforça a relevância deste estudo, inclusive para o desenvolvimento e aprofundamento da discussão.

Assim, de posse das informações atinentes à formação continuada dos professores, fez-se coleta de dados junto ao NTE-Natal, através de uma tabela préelaborada, contendo os cursos ofertados no período de 2010 até 2014, com informações colhidas na página web do NTE-Natal (http://www.ntenatal.net/nte). Após isso, obteve- 
se, por e-mail, da coordenação do NTE informações sobre os cursos com os referentes turnos de oferta e a quantidade de professores-cursistas matriculados e concludentes. Foram fornecidos dados relativos apenas ao período de 2010 a 2013. Até a data de produção deste artigo, os dados de 2014, de acordo com a coordenação do NTE-Natal, ainda não tinham sido tabulados pela instituição, assim como os de 2015, mas pelo fato de que os cursos estarem em andamento.

Com a disponibilização das informações pela coordenação do NTE-Natal, passamos à fase de análise do conteúdo através da tabulação de dados, dentro do que foi proposto como objetivo. Primeiramente foram tratados os dados referentes aos cursos por turno de execução, para obter uma relação entre turnos e cursos mais frequentemente escolhidos pelos professores. Em seguida, foi feita a tabulação entre os cursos e a quantidade de professores-cursistas matriculados e concludentes, para obter o índice de aproveitamento nos cursos e turnos oferecidos. Sobre esses dados, apresentamos a discussão a seguir.

\section{Análise dos Dados: o Potencial Formativo do NTE-Natal}

De posse dos dados, chegamos ao montante de 37 cursos ofertados no período de 2010 a 2013. Com uma média de aproximadamente 11 cursos por semestre (Gráfico 1). Um ponto importante visto nesse gráfico é o aumento de cursos oferecidos no semestre 2011.2 e logo após uma queda significativa dessa quantidade em 2012.1 e 2012.2.

Gráfico 1. Quantidade e média de cursos oferecidos por semestre

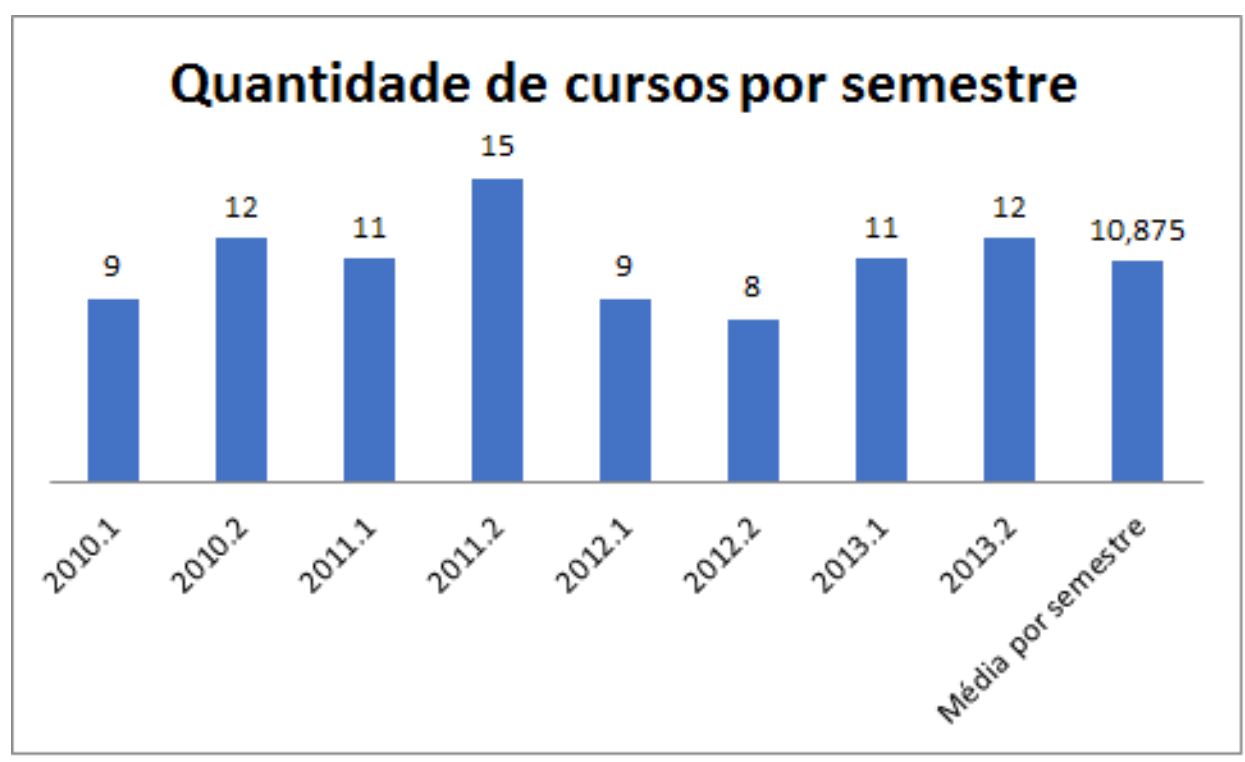

Fonte: Elaborado pelos autores.

Vale destacar também a variedade de cursos oferecidos e que contemplam aspectos tanto técnicos, quanto pedagógicos das TIC. Além de cursos voltados para a apropriação de computadores e softwares básicos, como sistema operacional, suíte de escritório e internet, os considerados cursos de informática básica, o NTE-Natal oferta cursos que exploram desde a produção e edição de vídeos, uso de ambientes virtuais de aprendizagem e ferramentas da web 2.0, como blogs, aplicativos em nuvem, Google Drive entre outros, a cursos sobre manutenção e instalação de programas. Tais conhecimentos são necessários para que os professores, tanto de sala de aula quanto dos 
laboratórios, saibam operar os equipamentos e softwares disponíveis para explorarem em suas aulas.

A categoria de cursos voltados para utilização e produção de conteúdos é responsável por $84 \%$ das formações oferecidas (Gráfico 2). Isto evidencia que o referido NTE cumpre os propósitos aos quais fora designado quando se trata da quantidade de ofertas de cursos para a utilização pedagógica das TIC, visto que cada curso contempla diferentes recursos e diferentes ementas.

Gráfico 2. Categoria de cursos oferecidos pelo NTE-Natal

\section{Porcentagem da certificação e desistência dos cursos oferecidos}

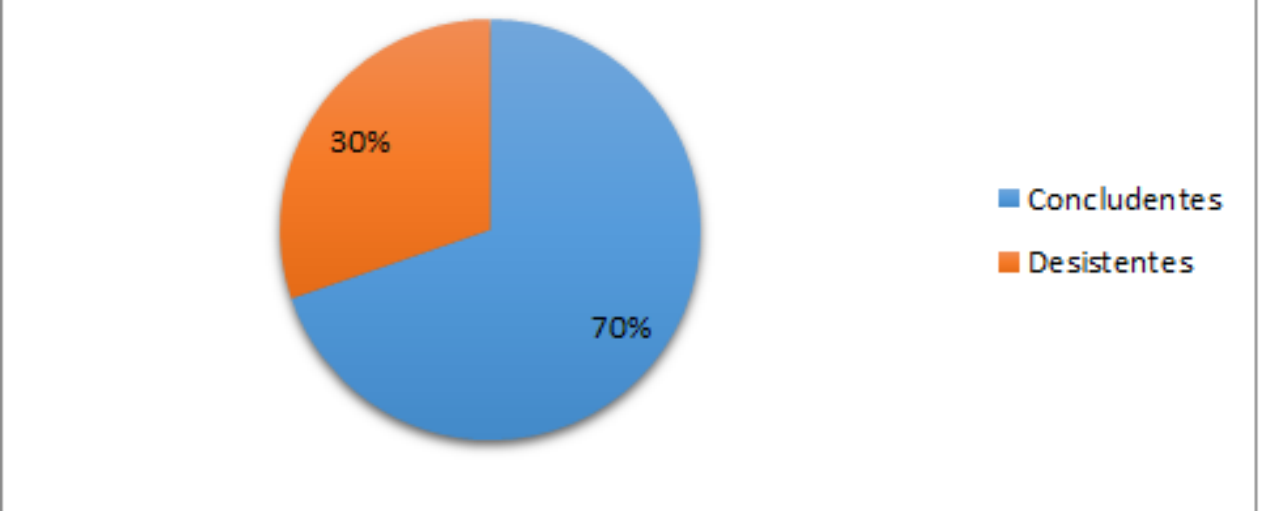

Fonte: Elaborado pelos autores.

No que diz respeito ao potencial formativo, no período analisado, das 1.954 matrículas realizadas nos 37 cursos, 1.362 lograram a certificação. Convém lembrarmos que um único professor pode representar mais de uma matrícula, uma vez que ele pode escolher e realizar mais de um curso. Neste trabalho, não conseguimos captar os motivos que levaram 30\% dos professores-cursistas desistirem dos cursos (Gráfico 3). Apesar disso, consideramos que o expressivo número de formados, indica a responsabilidade e relevância do NTE-Natal como espaço para formação continuada de professores da capital potiguar para o uso pedagógico das TIC. 
Gráfico 3. Certificações e desistências dos cursos oferecidos pelo NTE-Natal

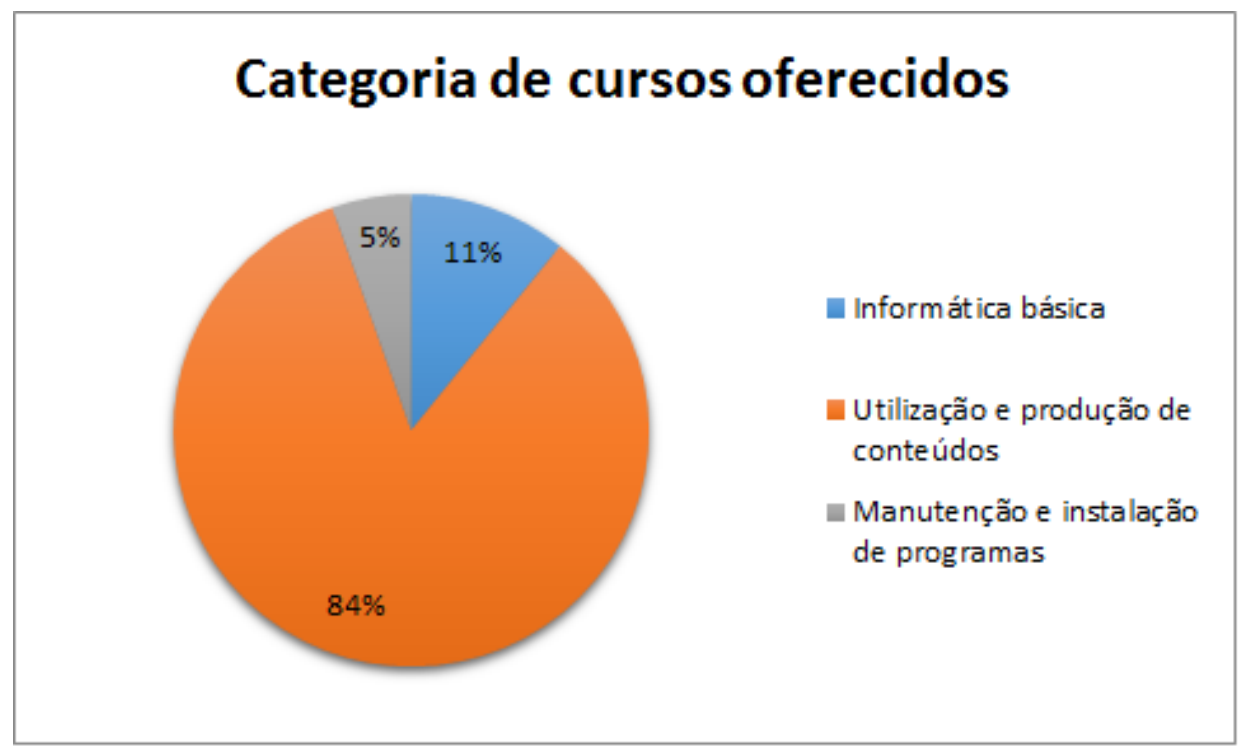

Fonte: Elaborado pelos autores.

Para exemplificar essa desistência, analisamos os cursos "Informática Básica" e "Linux Educacional", considerados como pré-requisito para todos os demais e com maior número de matrícula - 402 e 198, respectivamente. Um ponto relevante que observamos foi o fato de a disciplina "Linux Educacional" não ter sido mais oferecida a partir do semestre 2011.2. Por outro lado, notamos aumento nas inscrições do curso "Informática Básica", que não foi oferecido em 2013.2. Consideramos que isto precisa ser analisado, visto que se trata de uma disciplina porta de entrada para os professorescursistas na área da formação.

Destacamos ainda que os índices de desistência são semelhantes ao geral, que foi $30 \%$ conforme anteriormente apresentado no Gráfico 3. Enquanto em "Informática Básica", 25\% não concluem o curso, em "Linux Educacional", aproximadamente, 30\% abandonam a formação. Para estes cursos, especificamente, consideramos os índices de desistências altos por se tratarem de cursos introdutórios e de importância elevada na formação continuada do NTE, já que são pré-requisitos para outros. Todavia, há cursos com desistência ainda maior, superando $50 \%$ das inscrições, como é o caso do curso de "Informática Básica II", no turno da tarde. A partir desses dados, indicamos a necessidade de um estudo sobre os fatores que estejam contribuindo para um elevado índice de desistência, que suponhamos que possam estar relacionais à ementa, turno, nível de dificuldade até fatores pessoais.

Apesar disso, consideramos que há bastante flexibilidade e diversidade de horário na oferta dos cursos pelo NTE-Natal. Além de ofertar cursos na modalidade semipresencial, o NTE buscou contemplar os três turnos. Com isto, amplia-se o leque de opções de cursos que o professor pode se matricular, conforme sua disponibilidade de tempo. Dos 37 cursos ofertados no período analisado, 20 aconteceram pela manhã, 26 a tarde e 19 a noite. Registramos que 13 deles foram ofertados nos três turnos, com

1 Sistema operacional dos computadores fornecidos e distribuídos pelo Ministério da Educação, através do PROINFO, para a instalação de laboratórios de informática educativa. 
destaque para aqueles considerados sem pré-requisito, portanto, básicos. É importante ressaltar que cursos oferecidos em dois ou mais turnos são responsáveis por quase $85 \%$ das inscrições. A tabela 1, mostra que os cursos ofertados em mais de um turno, mesmo proporcionalmente, conseguem captar maior número de professores-cursistas.

Tabela 1. Número de Professores por Quantidade de Turnos

\begin{tabular}{|c|c|c|}
\hline $\begin{array}{c}\text { Quantidade de } \\
\text { Turnos }\end{array}$ & $\begin{array}{c}\text { Quantidade de } \\
\text { Inscritos }\end{array}$ & Percentual (\%) \\
\hline Um Turno & 294 & 15,05 \\
\hline Dois ou mais Turnos & 1660 & 84,95 \\
\hline Total & $\mathbf{1 9 5 4}$ & $\mathbf{1 0 0}$ \\
\hline
\end{tabular}

Fonte: Elaborada pelos autores.

É oportuno que o NTE-Natal procure identificar os motivos pelos quais alguns cursos foram ofertados em apenas um turno durante os três anos analisados. Entre os fatores podem estar infraestrutura, corpo docente ou mesmo baixa procura dos professores. Isso fica bem característico quando se observa a quantidade de inscritos nas disciplinas oferecidas apenas em um turno.

Por fim, registramos a ausência de cursos que explorem softwares educativos e objetos de aprendizagem (OA). Nicoleit, Giacomazzo e Gonçalves (2014) destacam a necessidade de explorar na formação continuada de professores, além de procedimentos metodológicos e práticas de uso das TIC, o uso e avaliação de tais recursos. Mesmo com a existência de milhares de projetos dessa natureza, inclusive com acesso livre e gratuito, não identificamos cursos que oportunizem os professores a conhecerem as possibilidades pedagógicas desses recursos didáticos multimidiáticos. Como o NTENatal tem como uma de suas missões incentivar o uso de recursos didáticos auxiliares nos processos de ensino e de aprendizagem, é relevante que procure adicionar nos próximos semestres formações voltados para a pesquisa e uso de tais recursos educativos digitais.

\section{Considerações Finais}

Com este estudo, identificamos a relevância do trabalho realizado pelo NTE-Natal na formação continuada dos professores da Rede Municipal de Ensino de Natal para o uso pedagógico das TIC. Isto se traduz no esforço de ofertar grande variedade de cursos por semestre, no período analisado. Consideramos que estas ações contribuem para inserir os professores no contexto de evolução profissional exigido na sociedade atual.

Julgamos que não basta apenas a equipe do NTE-Natal promover essa política de inserção e aprimoramento profissional dos professores, se os mesmos não tiverem o incentivo da gestão escolar e municipal, bem como o próprio desejo de aprimorar-se, ante as dificuldades sociais e profissionais que enfrentam diariamente. Vale lembrar que no foco de todo esse processo também estão os alunos que precisam de novas estratégias para desenvolver os conceitos das diversas áreas do conhecimento e, efetivamente, exercerem sua cidadania.

Apesar de ser oferecida uma variedade de cursos em ferramentas digitais, destacamos a necessidade de oferta de cursos sobre o uso de softwares educativos e OA. 
Tais recursos podem ampliar as possibilidades que os professores podem se servir para utilizar com seus alunos. O Linux Educacional, sistema operacional a qual os professores foram formados traz uma série de recursos neste sentido.

Finalmente, conhecer os motivos que levaram os professores a desistirem dos cursos devem ser analisados e, portanto, sugerem outras pesquisas. Compreendendo o papel do NTE-Natal como vetor importante na formação de professores nesta área, consideramos que os possíveis motivos de desistência aqui levantados devem ser considerados com o fito de subsidiar o aprimoramento do planejamento das próximas formações dos professores.

Para ampliar a concepção sobre o potencial formativo do referido núcleo, consideramos oportunas futuras investigações que possibilitem conhecer os impactos das formações na prática dos professores-cursistas para uma melhor apreensão da contribuição do NTE e seus cursos no sistema de ensino do município. Contudo, por hora, esperamos com este artigo contribuir com as políticas e ofertas de cursos de formação continuada sobre TIC para professores da Grande Natal e colaborar para a melhoria da Educação do Estado.

\section{Referências}

Maia, D. L.; Barreto, M. C. (2012). “Tecnologias digitais na educação: uma análise das políticas públicas brasileiras". Educação, Formação \& Tecnologias, 5 (1), 47-61 [Online], Disponível em: 〈http://eft.educom.pt $\rangle$. Acesso em: 17 abr. 2015.

Mercado L. P. L. (2009). "Formação Continuada de Professores e Novas Tecnologias". Maceió: Edufal.

Nicoleit, E. R.; Gonçalves, L. L.; Giacomazzo, G. F. (2014). "Formação de Professores da Rede Municipal de Educação para o uso de TIC". In: XIX Workshop de Informática na Escola (WIE 2014). Anais... Dourados, MS. Disponível em: $\langle$ http://www.br-ie.org/pub/index.php/wie/article/view/3298/2842>. Acesso em: 17 abr. 2015.

Portal da Prefeitura Municipal de Natal. Disponível em: <http://www.natal.rn.gov.br/sme/paginas/ctd-611.html>. Acesso em: 15 abr. 2015.

Quartiero, E. M. "Formação continuada de professores: o processo de trabalho nos Núcleos de Tecnologia Educacional (NTE)". In: XVIII SEMINÁRIO INTERNACIONAL DE FORMAÇÃO DE PROFESSORES PARA O MERCOSUL/CONE SUL. Anais... Florianópolis. Disponível em: $\langle$ http://seminarioformprof.ufsc.br/files/2010/12/QUARTIERO-Elisa-Maria3.pdf>>. Acesso em: 17 abr. 2015. 